RESEARCH PAPER RP1113

Part of Journal of Research of the National Bureau of Standards, Volume 21, July 1938

\title{
DISPLACEMENT OF NITROGEN FROM AND ITS SOLUTION IN CERTAIN REAGENTS DURING VOLUMETRIC GAS ANALYSIS
}

\author{
By Joseph R. Branham and Max Sucher
}

\section{ABSTRACT}

This paper deals with errors in volumetric gas analysis caused by the displacement of nitrogen from and its solution in liquid reagents when these are used to remove a reactive gas from a gas mixture. The data show that measurable volumes of nitrogen may be exchanged between the gas sample and the reagent, as well as between the atmosphere and the reagent at the surface of separation in the atmospheric arm of the absorption pipette. Volumetric errors may also result from the change of solubility of nitrogen in the reagent with temperature when heat is liberated during the absorption of a reactive gas. Errors from these sources are roughly proportional to the solubility of nitrogen in the reagents.

\section{CONTENTS}

Page

I. Introduction

II. Preparation and choice of solutions

III. Apparatus

IV. Experimental procedure

V. Displacement of oxygen and the solution of nitrogen in water and in several aqueous solutions._. 67

VI. Transfer of gas through the open surface of water and of several solutions in absorption pipettes. 68

VII. Approximate solubilities of nitrogen and of oxygen in the solutions examined...... 70

VIII. Effect of a floating oil seal on the passage of gas through the open surface

IX. Exclusion of air above the open surface by means of a nitrogen-filled rubber balloon. 73

X. Discussion of the data

XI. Change of solubility of nitrogen with temperature in solutions of alkaline potassium pyrogallate and of chromous sulfate

XII. Conclusion

\section{INTRODUCTION}

In volumetric gas analysis the apparent percentage of each reactive constituent of the sample of gas being analyzed is obtained from the change of volume which occurs when the reactive constituent is removed. This removal is accomplished chemically by passing the sample over or through, or shaking it with, appropriate liquid reagents. It is customary to saturate these reagents before the analysis with the inert gas of the sample and thereby fix the dissolved inert at an amount which can be reproduced during subsequent operations. Since the partial pressure of the inert gas in the sample is less than 
atmospheric, some of the gas dissolved in the reagent will be displaced during the passages which are required for the removal of the reactive constituent. Since the continued presence of this displaced gas in the gas phase would result in a low apparent percentage of the reactive constituent, the displaced gas is redissolved wholly or in part by repeated passages of the gas which remains after the chemistry of the analysis has been completed.

In the course of a series of experiments which were made to determine the suitability of chromous solutions ${ }^{1}$ as reagents for oxygen in gas analysis, the accuracy of the results was found to be affected by the displacement of nitrogen ${ }^{2}$ from, and its subsequent partial resolution in, the reagents. The present study was undertaken to find out why nitrogen was more readily transferred between the chromous solutions and the gas being analyzed than between potassium pyrogallate and samples of gas under similar conditions.

The data which are reported in this paper were obtained by measuring (1) the oxygen which was displaced, and (2) the nitrogen which dissolved when nitrogen was bubbled through several solutions which had previously been saturated with air. The first of these measurements is of the same nature as the displacement of nitrogen from a reagent during the chemical absorption of oxygen, while the second corresponds to the re-solution of any nitrogen which was displaced during the first few passages of the gas through the reagent.

\section{PREPARATION AND CHOICE OF SOLUTIONS}

Since the solutions were saturated with air at the start of the experiments, those which react chemically with oxygen could not be used to obtain the data desired. For this reason solutions of chromic chloride, chromic potassium sulfate, and potassium hydroxide were examined on the assumption that nitrogen would be transferred in them in a manner similar to its transfer in solutions of chromous chloride, chromous sulfate, and alkaline potassium pyrogallate. Airsaturated distilled water was also used to furnish a basis for comparison.

The solutions examined were:

1. A $4 M$ solution of green chromic chloride to which was added 10 percent by volume of concentrated hydrochloric acid. (The solutions of chromous chloride reported in RP1112 were prepared by reducing this mixture with amalgamated zinc.)

2. A $0.4 M$ solution of chromic potassium sulfate. (The solutions of chromous sulfate reported in RP1112 were prepared by reducing a solution of this concentration with amalgamated zinc.)

3. A solution prepared by adding $10 \mathrm{ml}$ of water to $100 \mathrm{ml}$ of a solution of potassium hydroxide with a specific gravity of 1.54 at $20^{\circ} \mathrm{C}$. (The concentration of potassium hydroxide in this solution is approximately the same as that used to prepare alkaline potassium pyrogallate in this laboratory.) ${ }^{3} \quad$ This solution of potassium hydroxide is approximately $12 \mathrm{~N}$.

4. A $3 N$ solution of potassium hydroxide. (This solution, which contains about 15 percent by weight of $\mathrm{KOH}$, was selected after the

\footnotetext{
$1 \mathrm{~J}$. R. Branham, Preparation and application of chromous solutions for the absorption of oxygen in volumetric gas analysis. J. Research NBS 21. 45 (1938) RP1112.

2 The term "nitrogen" is used throughout this paper to include the normal constituents of air after the removal of oxygen and carbon dioxide.

3 These solutions are prepared in the manner recommended by R. P. Anderson, J. Ind. Eng. Chem. 7, 578 (1915).
} 
more concentrated solutions of potassium hydroxide had been examined, in order to obtain additional data regarding the solubility and transfer of nitrogen.)

5. Distilled water.

All of these liquids were saturated by bubbling air freed from carbon dioxide through them before they were transferred to the absorption pipettes attached to the volumetric apparatus.

\section{APPARATUS}

The volumetric measurements were made over mercury in an apparatus previously described. ${ }^{4}$ The reproducibility of measurement of a fixed volume of gas in this apparatus is $\pm 0.02 \mathrm{ml}$. Each determination of the nitrogen which dissolved or the oxygen which was displaced depended on two volumetric measurements. When solutions of chromic chloride were examined three measurements were required because of the presence of carbon dioxide (see section IV). Errors of volumetric measurement are carried forward during the examination of each solution and become more significant the less the solubility of nitrogen. The mesaured volumes of gas were reduced to $0^{\circ} \mathrm{C}$ and to a pressure of $760 \mathrm{~mm}$ of $\mathrm{Hg}$ before being plotted.

The air-saturated solutions were examined in two Schott \& Genossen absorption pipettes. These are equipped with fritted-glass distributor tips of "porosity G2." ${ }_{5}$ The oxygen displaced from the various solutions was determined by absorption in alkaline potassium pyrogallate.

\section{EXPERIMENTAL PROCEDURE}

The following procedure was employed to measure the volumes of nitrogen and oxygen transferred between the various air-saturated solutions and the nitrogen which was bubbled through them.

1. Approximately $220 \mathrm{ml}$ of one of the air-saturated solutions was put into each of two absorption pipettes.

2 . The volumetric apparatus, including the capillary connections above the solution in the pipettes, was filled with nitrogen. The open surface of the liquid in one pipette was in contact with an atmosphere of air (fig. 1, case 1).

3. An atmosphere of nitrogen (or an oil seal) was imposed above the open surface in the other pipette (fig. 1, case 2).

4. Approximately $60 \mathrm{ml}$ of nitrogen was measured in the burette and passed 10 times through the solution in one of the two pipettes. (When nitrogen was passed through the water, 5, instead of 10 , passages were made initially.)

5. The gas which had lost some nitrogen to the solution and had gained some oxygen from it was brought back into the burette and measured.

6. The volume of oxygen gained was determined by absorption in potassium pyrogallate. The residue which now remained was a measured quantity of nitrogen which was immediately used to repeat the procedure with the solution in the second pipette, beginning with step 4.

The volume of nitrogen which dissolved in the liquids during the passages of step 4 in each case was calculated by subtracting the

4 Martin Shepherd, BS J. Research 6, 121 (1931) RP266.

5 These are listed as 153-SG2 in catalog of Fish-Schurman Corporation, New York City. 
volume after step 6 from the volume at the beginning of step 4 . Since the measurements were made alternately under the conditions of case 1 and case 2, the observed volume after step 6 of case 1 (or case 2) becomes automatically the initial volume of step 4 in the other case which followed.

In the calculations, this quantity is the subtrahend in one case and the minuend in the case immediately following. For this reason an error of measurement at this point affects the calculated volume of dissolved nitrogen equally but in opposite directions in any two successive determinations. The errors of this particular measurement

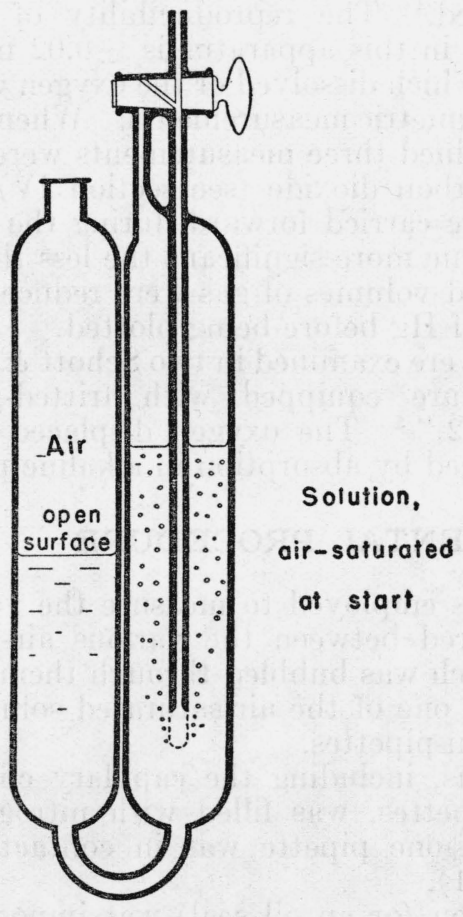

CASE I

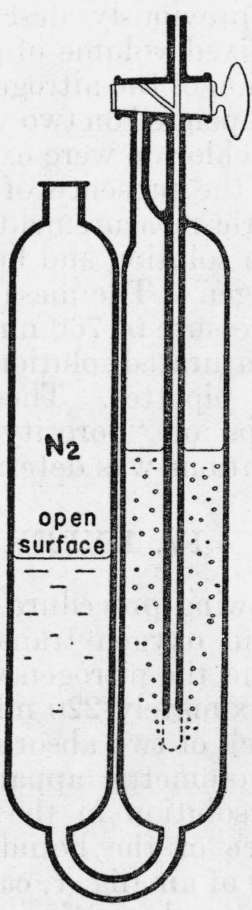

CASE 2

Figure 1.-Absorption pipettes in cases 1 and 2.

will, therefore, affect the series of data for each case, taken separately, but cancel if the data for the two cases are averaged.

The procedure, with each of the liquids examined, was repeated at fairly regular intervals except during the overnight recess. About 24 hours elapsed between the first and seventieth passages in each set of experiments.

When nitrogen was passed through a saturated solution of green chromic chloride, which had previously been acidified with hydrochloric acid and had had carbon dioxide-free air bubbled through it for 18 hours, carbon dioxide was found in the emergent nitrogen. The volumes of carbon dioxide were readily measurable, ranging up to $0.2 \mathrm{ml}$, and were roughly proportional to the time which elapsed between two series of passages of nitrogen through the acidified 
solution. The identification of the gas was made by passing carbon dioxide-free air through the acidified solution and then through solutions of calcium hydroxide and lead acetate. The calcium and lead salts which precipitated were examined microscopically ${ }^{6}$ and identified as $\mathrm{CaCO}_{3}$ and $\mathrm{PbCO}_{3}$. The nearly constant rate of evolution of carbon dioxide from the acidified solutions containing chromic chloride suggests the presence of carbonate combined with chromium in a manner similar to the relation which exists between part of the chlorine in green chromic chloride and the chromium in that molecule. ${ }^{7}$

When this solution was used to obtain the data given in figure 4 (C) it was necessary to remove the carbon dioxide which was displaced from it before the oxygen could be determined. ${ }^{8}$ This was done by passing the gas containing carbon dioxide through a $12 \mathrm{~N}$ solution of KOH. This extra step in the procedure may have been responsible for some of the irregularities observed in the data given in figure 4 (C).

\section{DISPLACEMENT OF OXYGEN AND THE SOLUTION OF NITROGEN IN WATER AND IN SEVERAL AQUEOUS SOLUTIONS}

The data given in figures 2,3 , and 4 resulted from the series of operations described in section IV. The open surface of one portion of liquid in the atmospheric arm of absorption pipette $A$ was in direct contact with air (case 1, fig. 1), while the open surface of the second portion was in pipette $B$ in direct contact with an atmosphere of nitrogen (case 2, fig. 1). ${ }^{9}$

The open circles represent the volumes of oxygen which were displaced in case 1, the closed circles are the volumes of oxygen displaced in case 2. The open triangles are the volumes of nitrogen which were dissolved in case 1 and the closed triangles those which dissolved in case 2. The observed volumes have been multiplied by correction factors, which vary from 0.87 to 0.89 , to reduce them to $0^{\circ} \mathrm{C}, 760-\mathrm{mm}$ pressure. Theoretically, the uncorrected data may be more directly comparable than the corrected data, but since the difference between the correction factors is small there is some advantage in correcting to standard conditions.

The upper horizontal broken line in figure 2 is the volume of oxygen, at $0^{\circ} \mathrm{C}, 760-\mathrm{mm}$ pressure, calculated as present in $220 \mathrm{ml}$ of water saturated with air at the atmospheric pressure and temperature which prevailed when the data in figure 2 were secured. Similarly, the lower horizontal broken line in figure 2 is the volume of nitrogen reduced to standard conditions calculated as the difference between the nitrogen in $220 \mathrm{ml}$ of air-saturated water and of nitrogen-saturated water. These values were calculated by Henry's law from the solubilities ${ }^{10}$

6 This work was done by Charles P. Saylor of this laboratory.

7 J. Olie, Jr., investigated the equilibrium between the green and violet chromic chlorides. He found that only one of the three chlorine atoms in freshly prepared green chromic chloride could be precipitated by silver nitrate. If, however, the solution was aged before adding the silver nitrate, the percentage of chlorine which reacted increased with the age of the solution. Z. anorg. Chem. 29, 51 (1906).

8 Anderson and Riffe have reported that a solution of chromous chloride prepared by reducing violet chromic chloride by a current of hydrogen at 400 to $500^{\circ} \mathrm{C}$, absorbs oxygen rapidly but not completely. The completeness of the absorption was measured by passing the residual gas, after treatment in $\mathrm{CrCl}_{2}$, through alkaline potassium pyrogallate. It is not known whether the chromous solution prepared by these authors evolved carbon dioxide, but if so, the apparent incomplete absorption of oxygen would be explained. J. Ind. Eng. Chem. 8, 24 (1916).

This atmosphere of nitrogen was maintained by connecting the atmospheric arm of pipette $B$ to the burette arm of an extra pipette which contained alkaline potassium pyrogallate. The connections consisted of a rubber stopper, glass tubing and a butted glass joint covered with rubber tubing.

10 Winkler, Ber. deut. Chem. Ges. 24, 3606 (1891); Int. Crit. Tables. 3, 258 (1928). 
of oxygen and of nitrogen in water which is in equilibrium with a large surface of gas. Data calculated in this manner may differ from those reported in this paper, which were obtained by passing bubbles of gas through liquids. The broken curves in these figures are drawn through points midway between the volumes of oxygen displaced in case 1 and in case 2, and also midway between the volumes of nitrogen which dissolved in case 1 and in case 2. These points through which the broken curves are drawn will be referred to as average data. These data are used to calculate the curves given in figures 6 and 7 .

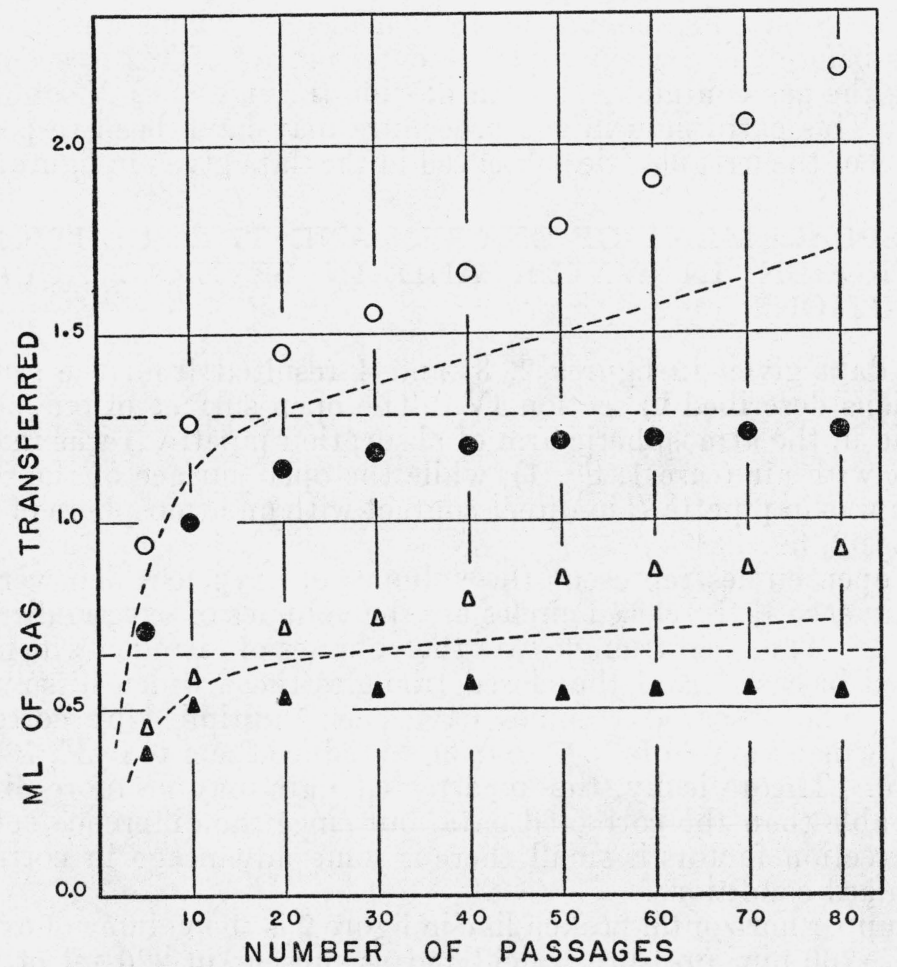

FIGURE 2.-Volumes of oxygen and nitrogen transferred between $220 \mathrm{ml}$ of water, originally air-saturated.

The nitrogen bubbled through it as measured in the burette, corrected to $0^{\circ} \mathrm{C}, 760-\mathrm{mm}$ pressure. Open circles represent oxygen liberated in case 1; filled circles, oxygen liberated in case 2; open triangles, nitrogen dissolved, case 1; filled triangles, nitrogen dissolved, case 2.

\section{TRANSFER OF GAS THROUGH THE OPEN SURFACE OF WATER AND OF SEVERAL SOLUTIONS IN ABSORPTION PIPETTES}

It is evident from figures 2,3 , and 4 that the nature of the atmosphere in contact with the open surface of air-saturated liquids has a marked effect on the data obtained when nitrogen is bubbled through them. When air is above the open surface (case 1, fig. 1) and oxygen is displaced from each liquid by the passage of nitrogen through it, some oxygen from the imposed atmosphere will dissolve in the liquid through its open surface, and subsequently be displaced and measured 


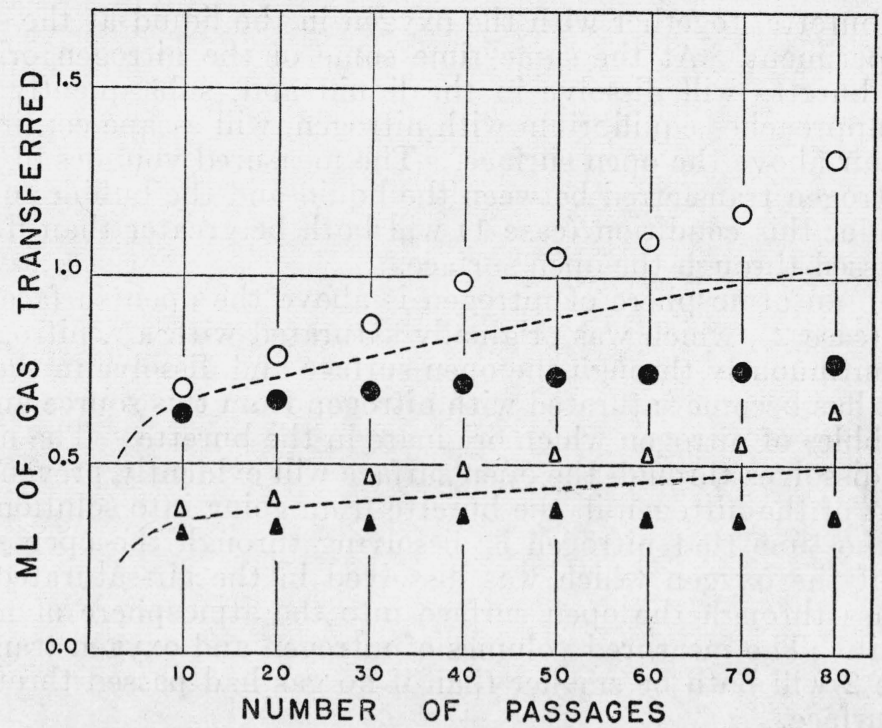

FIGURE 3.- Volumes of oxygen and nitrogen transferred between $220 \mathrm{ml}$ of $0.4 \mathrm{M}$ $\mathrm{K}_{2} \mathrm{Cr}_{2}\left(\mathrm{SO}_{4}\right)_{4}$ originally air-saturated.

The nitrogen bubbled through it as measured in the burette, corrected to $0^{\circ} \mathrm{C}, 760-\mathrm{mm}$ pressure. Symbols as in figure 2 .
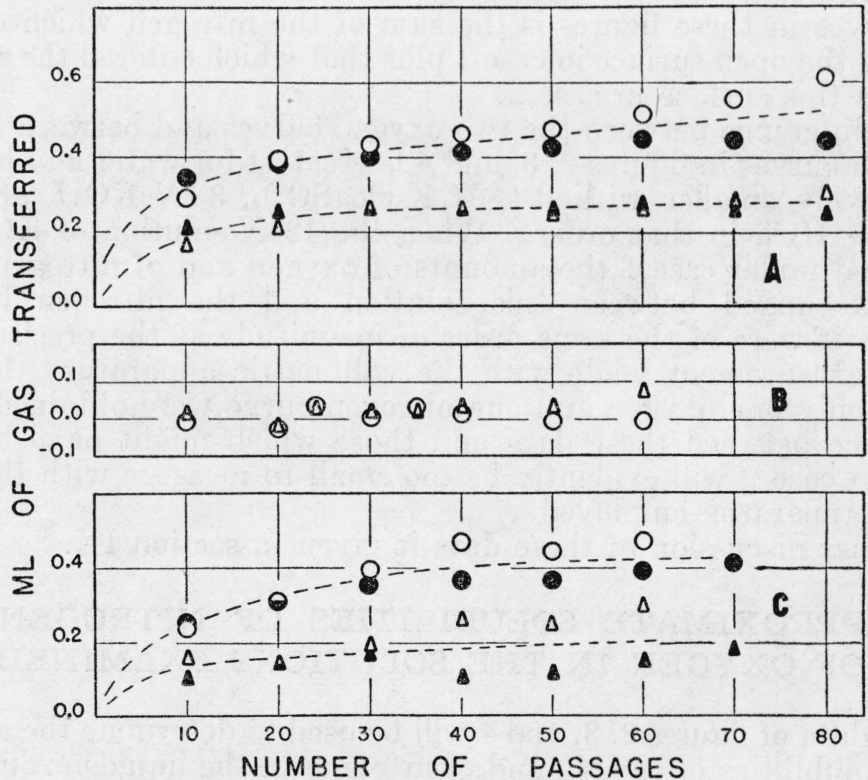

FIGURE 4.-Volumes of oxygen and nitrogen transferred between $220 \mathrm{ml}$ of $(A) 3 \mathrm{~N}$ $\mathrm{KOH},(B) 12 N \mathrm{KOH},(C) 4 M \mathrm{CrCl}_{3}+10$ percent of $\mathrm{HCl}$ by volume.

The solutions were initially saturated with air and the nitrogen bubbled through them, as measured in the burette, was corrected to $0^{\circ} \mathrm{C}, 760-\mathrm{mm}$ pressure. Symbols as in figure 2 . 
in the burette, together with the oxygen in the liquid at the start of the experiment. At the same time some of the nitrogen originally in the burette will dissolve in the liquid and, subsequently as the liquid approaches equilibrium with nitrogen, will escape continuously to the air above the open surface. The measured volumes of oxygen and nitrogen transferred between the liquid and the bubbles of nitrogen under this condition (case 1) will both be greater than if no gas had passed through the open surface.

When an atmosphere of nitrogen is above the open surface of the liquid (case 2), which was originally saturated with air, nitrogen will pass continuously through the open surface and dissolve in the liquid until it has become saturated with nitrogen from this source and from the bubbles of nitrogen which originate in the burette. The nitrogen which dissolves through the open surface will evidently prevent a like amount of the nitrogen in the burette from going into solution. ${ }^{11}$ At the same time that nitrogen is dissolving through the open surface, some of the oxygen which was dissolved in the air-saturated liquid will pass through the open surface into the atmosphere of nitrogen above it. The measured volumes of nitrogen and oxygen transferred in case 2 will both be smaller than if no gas had passed through the open surface.

The differences between each pair of oxygen curves shown in figures 2,3 , and 4 represent the oxygen which dissolved through the open surface of each liquid from the atmosphere of air (case 1) plus that which escaped from the liquid into the atmosphere of nitrogen above its open surface (case 2). Similarly, the differences between the nitrogen curves in these figures is the sum of the nitrogen which escaped through the open surface in case 1 plus that which entered the solution through this surface in case 2 .

The difference between the two oxygen curves and between the two nitrogen curves in figures 2, 3 , and 4 is greatest for water and becomes successively smaller with $0.4 M \mathrm{~K}_{2} \mathrm{Cr}_{2}\left(\mathrm{SO}_{4}\right)_{4}, 3 \mathrm{~N} \mathrm{KOH}$, and $4 M$ $\mathrm{CrCl}_{3}+\mathrm{HCl}$, in that order. When the $12 \mathrm{~N}$ solution of $\mathrm{KOH}$ was examined under case 1 the amounts of oxygen and of nitrogen which were exchanged between this solution and the nitrogen bubbled through it were of the same order of magnitude as the precision of a single measurement made with the volumetric apparatus. For this reason only one oxygen and one nitrogen curve were obtained. The difference between these data and those which might have been secured in case 2 will evidently be too small to measure with the volumetric apparatus employed.

Further discussion of these data is given in section IX.

\section{APPROXIMATE SOLUBILITIES OF NITROGEN AND OF OXYGEN IN THE SOLUTIONS EXAMINED}

The data of figures 2,3 , and 4 will be used to determine the approximate solubilities of oxygen and of nitrogen in the liquids examined in this work. These data must be considered from two standpoints; (1) The number of passages of nitrogen through the liquids required

\footnotetext{
11 Effects of this kind are to be expected to some extent whenever an atmosphere of nitrogen is above the open surface of a reagent which is only partially saturated with nitrogen. This source of error in volumetric gas analysis has been mentioned in paragraph 4 of the introduction and is discussed in section XII.
} 
to establish equilibrium and (2) the ordinate values corresponding to the number of passages chosen as indicative of equilibrium.

The passage of oxygen and nitrogen through the open surface of the liquids in the atmospheric arm of the absorption pipettes prevents the establishment of equilibrium under the conditions of case 1 . The number of passages of nitrogen required to equilibrate the liquids with nitrogen must, therefore, be based on the data obtained under the conditions of case 2 .

The shapes of the curves located by the position of the solid triangles in figures 2,3 , and 4 indicate that each of the liquids was substantially saturated with nitrogen during the first 30 passages of nitrogen through them. This indication is substantiated to some extent by the fact that the curve of the average data (fig. 2) and the horizontal line determined from saturation data intersect at about this abscissa.

The curves determined by the solid circles continue slightly upward beyond abscissa 30 , about $0.05 \mathrm{ml}$ of oxygen apparently being displaced from each of the liquids except $12 \mathrm{~N} \mathrm{KOH}$ between the thirtieth and seventieth passages of nitrogen. Experiments made by confining atmospheric nitrogen in the volumetric apparatus and by passing the confined nitrogen through potassium pyrogallate after the nitrogen had been in the apparatus for several days showed that small amounts of oxygen had diffused into the apparatus. The rate of diffusion of oxygen into the apparatus was about $0.03 \mathrm{ml}$ each 24 hours. It is probable that this oxygen entered the volumetric apparatus through the short rubber connections which covered the butted glass joints between the various units which make up the volumetric apparatus. In view of this fact it is probable that no significant volumes of oxygen were displaced from the liquids by the passage of nitrogen through them after 30 passages had been made in the first few hours of experiments. However, since this is not certain, the data will be examined on the assumption that the liquids were in substantial equilibrium with nitrogen and contained no significant amounts of oxygen after the number of passages of nitrogen through them was somewhere between 30 and 50 .

As was shown in section VI, the amounts of nitrogen which had apparently dissolved in each of the liquids and the amounts of oxygen which were displaced from them are greater in case 1 and less in case 2 than they would have been if no gas had passed through the open surfaces in the atmospheric arm of the absorption pipettes. The solid triangles and circles between the thirtieth and fiftieth abscissas of figures 2, 3, and 4, therefore, lie below the ordinate values which would have been obtained at equilibrium if no gas had passed through the open surfaces. Similarly, the open circles and triangles lie above the ordinate values sought.

For convenience the average value of these two ordinates at 30 passages and the corresponding average at 50 passages were used to denote the approximate solubility of nitrogen and oxygen given in table 1. 
TABLE 1.-Average volume of nitrogen or oxygen transferred to or from $220 \mathrm{ml}$ of air-saturated solutions when nitrogen is bubbled through them until saturated

\begin{tabular}{|c|c|c|c|c|c|c|c|c|}
\hline 1 & 2 & 3 & 4 & 5 & 6 & 7 & 8 & 9 \\
\hline \multirow{2}{*}{ Liquid } & $\underset{\text { of } \mathrm{N}_{2}}{\text { Avg ml }}$ & $\begin{array}{c}\mathrm{Avg} \mathrm{ml} \\
\text { of } \mathrm{O}_{2}\end{array}$ & $\underset{\text { ratio }}{\mathrm{N}_{2}}$ & $\underset{\text { ratio }}{\mathrm{O}_{2}}$ & $\underset{\text { of } \mathrm{N}_{2}}{\operatorname{Avg~ml}}$ & $\begin{array}{c}\text { Avg ml } \\
\text { of } \mathrm{O}_{2}\end{array}$ & $\begin{array}{l}\mathrm{N}_{2} \\
\text { ratio }\end{array}$ & $\underset{\text { ratio }}{\mathrm{O}_{2}}$ \\
\hline & \multicolumn{4}{|c|}{30 passages } & \multicolumn{4}{|c|}{50 passages } \\
\hline $\begin{array}{l}\text { Water } \\
0.4 M \mathrm{~K}_{2} \mathrm{Cr}_{2}\left(\mathrm{SO}_{4}\right)_{4} \\
3 \mathrm{NKOH} \\
4 \mathrm{M} \mathrm{CrCl}_{3}+10 \text { percent of } \mathrm{HCl} \\
12 \mathrm{~K} \mathrm{KOH}\end{array}$ & $\begin{array}{l}0.66 \\
.41 \\
.26 \\
.18 \\
.03 ?\end{array}$ & $\begin{array}{l}1.36 \\
.79 \\
.42 \\
.37 \\
.00 ?\end{array}$ & $\begin{array}{l}1.0 \\
1.6 \\
2.5 \\
3.7 \\
20 ?\end{array}$ & $\begin{array}{l}\text { 1. } 0 \\
1.7 \\
3.2 \\
3.7 \\
20 \text { ? }\end{array}$ & $\begin{array}{l}0.69 \\
.43 \\
.26 \\
.19 \\
.03 ?\end{array}$ & $\begin{array}{l}1.49 \\
.89 \\
.46 \\
.42 \\
.00 ?\end{array}$ & $\begin{array}{l}1.0 \\
1.6 \\
2.6 \\
3.6 \\
20 ?\end{array}$ & $\begin{array}{l}1.0 \\
1.7 \\
3.3 \\
3.6 \\
20 ?\end{array}$ \\
\hline
\end{tabular}

The ratios of the volume of nitrogen which dissolved in water to the volumes of nitrogen which dissolved in each of the solutions are given in columns 4 and 8 . Similar ratios for the displaced oxygen are given in columns 5 and 9 . It may be noted that these ratios are substantially independent of the number of passages chosen as the criterion of equilibrium. These ratios are used to calculate the data given in figures 6 and 7 .

The approximate total volumes of nitrogen dissolved in $220 \mathrm{ml}$ of the solutions examined when these are in equilibrium with nitrogen are given in column 2 of table 2 . These values were obtained from the average of columns 2 and 6 of table 1 by multiplying by $1 /(1-0.7905)$ in accordance with Henry's law. Column 3 of table 2 is included for the benefit of readers who use larger or smaller volumes of reagents in absorption pipettes.

TABLE 2.-Approximate total volumes of nitrogen dissolved in several solutions

\begin{tabular}{l|r|r}
\hline & $\begin{array}{c}\text { Milliliters } \\
\text { of } \mathrm{N}_{2} \text { in } \\
220 \mathrm{ml}\end{array}$ & $\begin{array}{c}\text { Milliliters } \\
\text { of } \mathrm{N}_{2} \text { in } \\
100 \mathrm{ml}\end{array}$ \\
\hline Water & 3.2 & 1.5 \\
$0.4 \mathrm{M} \mathrm{K}_{2} \mathrm{Cr}_{2}\left(\mathrm{SO}_{4}\right)_{4}$ & 2.0 & .9 \\
$4 \mathrm{KOH}$ & 1.2 & .6 \\
$12 \mathrm{~N} \mathrm{KOH}$ (estimated) or alkaline potassium pyrogallate- & .9 \\
\hline
\end{tabular}

On the basis of the assumption made in the first paragraph of section II, $220 \mathrm{ml}$ of chromous sulfate, chromous chloride, and alkaline potassium pyrogallate, respectively, will contain approximately $2.0,0.9$, and $0.2 \mathrm{ml}$ of dissolved nitrogen when saturated with this gas under laboratory conditions. In other words, these are the volumes of dissolved nitrogen in these reagents at the beginning of an analysis and also those which must be in solution at the end of the analysis if the analytical results are to be correct.

\section{EFFECT OF A FLOATING OIL SEAL ON THE PAS- SAGE OF GAS THROUGH THE OPEN SURFACE}

The data given in figure 5 were obtained from two $220-\mathrm{ml}$ portions of water which were saturated with air at $23.5^{\circ} \mathrm{C}$ and $753-\mathrm{mm}$ pressure. The open circles and triangles represent the volumes of oxygen and nitrogen which were transferred when the open surface of the 
water was in direct contact with air (case 1). The closed circles and triangles represent the corresponding volumes of oxygen and nitrogen which were transferred when a 1-inch layer of liquid petrolatum floated on the open surface of the water and prevented direct contact between it and air. The horizontal broken lines have the same significance as in figure 2 . The volumes of dissolved oxygen and nitrogen in the layer of liquid petrolatum are not known. Approximately 24 hours elapsed between the first and seventieth passages of nitrogen through the water in the pipettes.

The curves indicate that the oil seal does not prevent the passage of oxygen and nitrogen through the open surface of the water. The

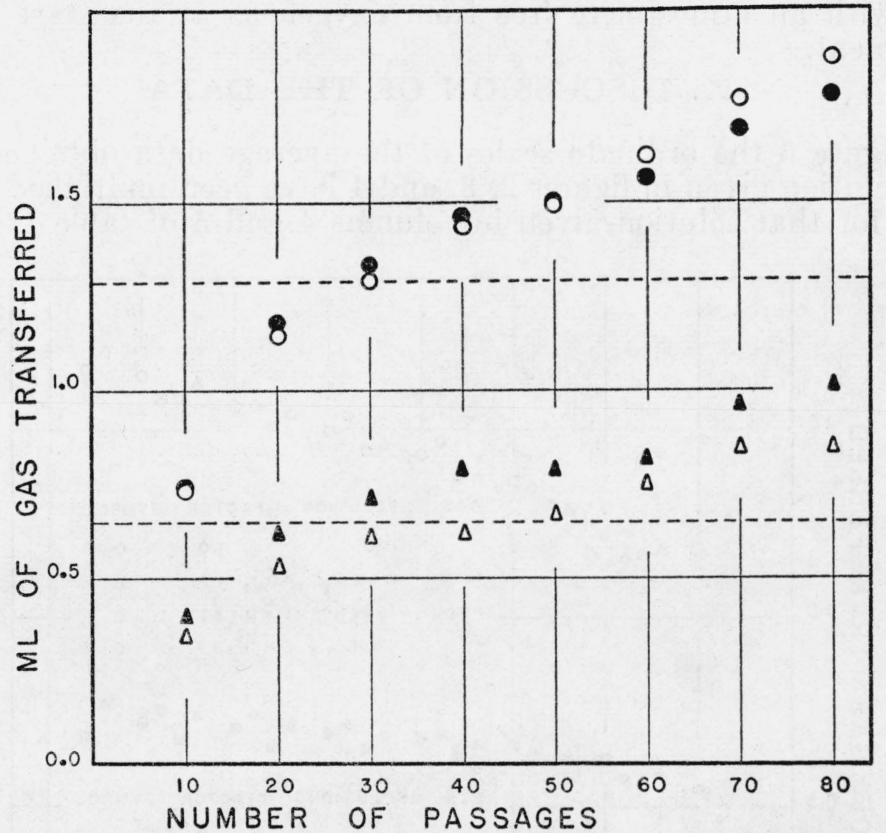

FigURE 5.-The volumes of oxygen and of nitrogen transferred between $220 \mathrm{ml}$ of water, originally air-saturated.

The nitrogen bubbled through it when the open surfaces were in contact with air and when covered by an oil seal.

escape of nitrogen under these conditions will prevent the establishment of an equilibrium between the water and the nitrogen which is bubbled through it and, if such an equilibrium is approached, the layer of oil will not preserve this condition for any extended period of time.

\section{EXCLUSION OF AIR ABOVE THE OPEN SURFACE BY MEANS OF A NITROGEN-FILLED RUBBER BALLOON}

Data were obtained when the open surface of air-saturated water was kept under an atmosphere of nitrogen by means of a balloon which was inflated with nitrogen just before the start of the experiment. Under these conditions there was little or no difference be- 
tween the rate of transfer of nitrogen in this pipette and in a pipette where an atmosphere of nitrogen was maintained by connections to an extra pipette containing potassium pyrogallate. In view of the fact that oxygen and nitrogen pass through rubber rather readily this result was surprising. There is little doubt, however, that the nitrogen-filled balloon, over the period of 3 days covered by the measurements, offered much better protection against the passage of oxygen through the atmospheric arm of a pipette than a 1-inch layer of liquid petrolatum. It does not follow, however, that as ordinarily used the rubber balloon will offer better protection than the oil seal. Balloons are usually left in place for a long time and may approach approximate equilibrium with the surrounding air instead of being filled with an atmosphere free from oxygen as at the start of this experiment.

\section{DISCUSSION OF THE DATA}

In figure 6 the ordinate scales of the average data obtained from each solution given in figures 2,3 , and 4 have been multiplied by the factor for that solution given in columns 4 and 5 of table 1 . Simi-

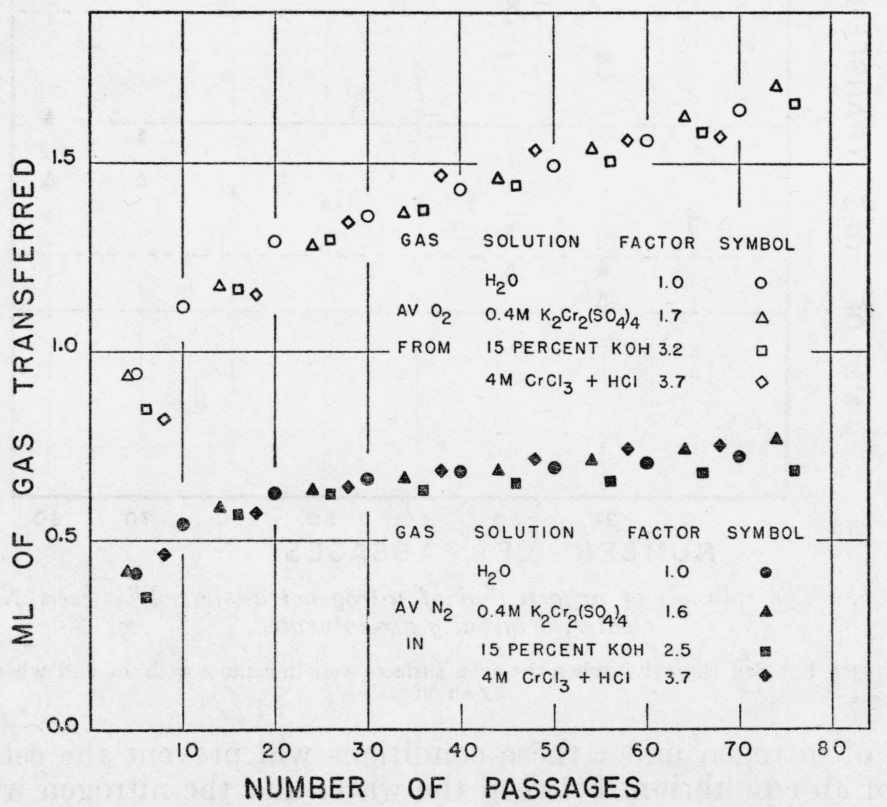

FIGURE 6.-Data from figures 2,3 , and 4 on vertical scales multiplied by the solubility factor based on 30 passages of nitrogen.

larly, figure 7 was obtained by multiplying these average data by the factor given in columns 8 and 9 of table 1. This treatment automatically brings the data from each solution into agreement with water at the ordinate corresponding to 30 passages of nitrogen in figure 6 and 50 passages of nitrogen in figure 7. It will not, however, secure agreement at other points unless the location of these points is proportional to the relative "solubilities" of oxygen and of nitrogen in the solutions examined. The agreement among the data in figures 
6 and 7 during the first 20 passages of nitrogen through the liquids is not as close as in the remainder of the passages. It is probable that the influence of the size of the bubbles ${ }^{12}$ of nitrogen, as well as experimental errors, may have affected these results.

Some of the conclusions to be drawn from the fairly good agreement between the data for various solutions when treated as described are of general importance in volumetric gas analyses which employ absorption methods. These may be summarized as follows.

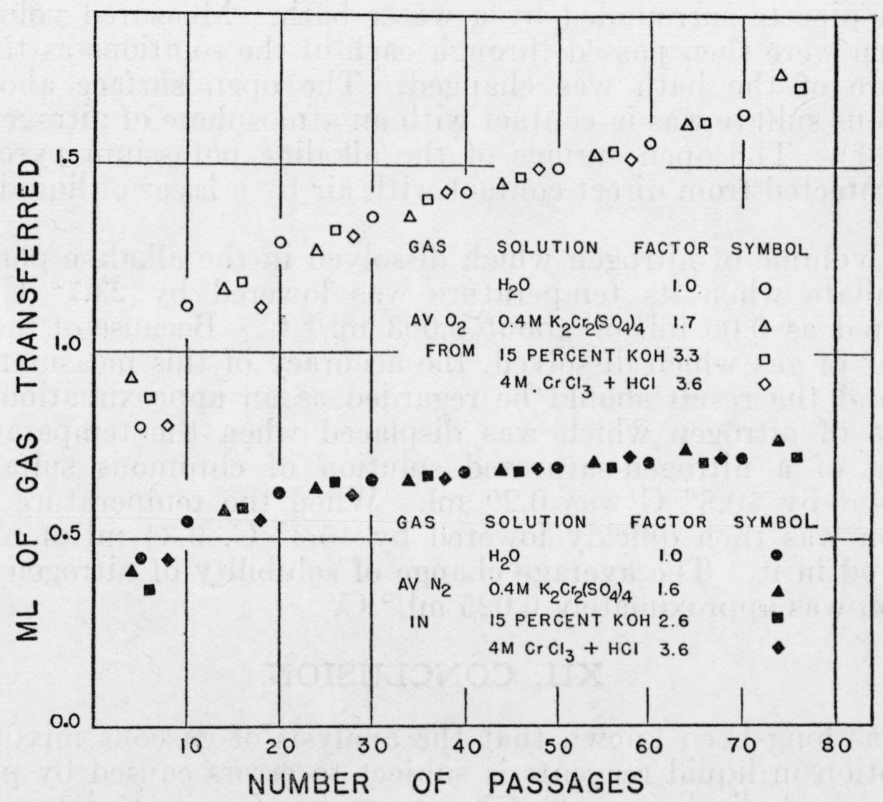

Figure 7.-Data from figures 2,3 , and 4 on vertical scales multiplied by the solubility factor based on 50 passages of nitrogen.

The solubility of nitrogen in a reagent saturated with it determines approximately: (1) The amount of this gas which passes through the open surface of the solution in the atmospheric arm of the absorption pipette under a given set of conditions; (2) the amount of nitrogen which will be displaced from the solution during the first few passages of a gas sample through it; and (3) the rate at which this displaced nitrogen may be redissolved by repeated passages of nitrogen through the solution. Similarly, the amounts of oxygen which pass from the atmosphere through the open surface of solutions with which oxygen does not react, are proportional to the solubility of oxygen in the particular reagents.

12 Data were obtained under the conditions of case 1 with an air-saturated solution of concentrated sulfuric acid. The nitrogen bubbles in this solution were noticeably larger than those in the other solutions which were studied. During the first 50 passages of nitrogen through this solution more oxygen and nitrogen were transferred between it and the nitrogen bubbles than with $0.4 M \mathrm{~K}_{2} \mathrm{Cr}_{2}\left(\mathrm{SO}_{4}\right)_{4}$. During the earlier passages, however, the data from the acid lay below the corresponding data from the $0.4 \mathrm{M} \mathrm{K}_{2} \mathrm{Cr}_{2}\left(\mathrm{SO}_{4}\right)_{4}$. The differences of slope between these results are attributed to the smaller area of contact from a given volume of nitrogen exposed by the larger bubbles. 


\section{CHANGE OF SOLUBILITY OF NITROGEN WITH TEMPERATURE IN SOLUTIONS OF ALKALINE POTASSIUM PYROGALLATE AND OF CHROMOUS SULFATE}

Several experiments were made to measure directly the effects of changes of temperature on the solubility of nitrogen in alkaline potassium pyrogallate and in chromous sulfate. ${ }^{13}$ A $220-\mathrm{ml}$ portion of each of these solutions was saturated by bubbling nitrogen through it in a pipette surrounded by a water bath. Measured volumes of nitrogen were then passed through each of the solutions as the temperature of the bath was changed. The open surface above the chromous sulfate was in contact with an atmosphere of nitrogen (case 2, fig. 1). The open surface of the alkaline potassium pyrogallate was protected from direct contact with air by a layer of liquid petrolatum.

The volume of nitrogen which dissolved in the alkaline potassium pyrogallate when its temperature was lowered by $23.7^{\circ}$ C. $^{14}$ was measured as $0.06 \mathrm{ml}$, or about $0.003 \mathrm{ml} /{ }^{\circ} \mathrm{C}$. Because of the small amount of gas which dissolved, the accuracy of this measurement is poor and the result should be regarded as an approximation. The volume of nitrogen which was displaced when the temperature of $220 \mathrm{ml}$ of a nitrogen-saturated solution of chromous sulfate was increased by $10.8^{\circ} \mathrm{C}$ was $0.29 \mathrm{ml}$. When the temperature of this solution was then quickly lowered by $15.3^{\circ} \mathrm{C}, 0.34 \mathrm{ml}$ of nitrogen dissolved in it. The average change of solubility of nitrogen in this solution was approximately $0.025 \mathrm{ml} /{ }^{\circ} \mathrm{C}$.

\section{CONCLUSION}

It has long been known that the analysis of gaseous mixtures by absorption in liquid reagents is subject to errors caused by physical solution and displacement of components of a gas mixture which themselves do not react chemically with the reagents. This paper reports experiments which illustrate the mechanics of the transfer of inert components between the samples of gas and the reagents. It is shown that when a mixture containing a reactive and an inert gas is passed through a liquid reagent which is saturated with the inert gas, the following things occur.

1. During the removal of the reactive gas in the first or the first few passages of the sample through the reagent measurable amounts of inert gas are displaced from solution.

2. The temperature of the reagent is raised by the heat of reaction with the reactive gas.

3. Because of conditions 1 and 2 the reagent now contains less inert and the gas phase more inert than at the start of the analysis.

4. If the temperature is lowered to the initial value and repeated passages of the gas made after the reaction is completed the reagent will again become saturated as at the beginning of the absorption. This requires much more time than is usually accorded in practice.

5. But even if condition 4 is reached the gas mixture which remains may not contain exactly the same amount of inert as was in the sample

\footnotetext{
${ }_{13}$ This solution was prepared by passing a $0.4 \mathrm{M}$ solution of $\mathrm{K}_{2} \mathrm{Cr}_{2}\left(\mathrm{SO}_{4}\right)_{4}$ over amalgamated zinc in a Jones reductor.

1f Temperatures were measured by a thermometer immersed below the open surface of these solutions.
} 
initially because of the passage of inert gas through the open surface of the reagent in the atmospheric arm of the absorption pipette during the analysis. The direction of this passage will depend upon the partial pressure of the inert gas in the atmospheric arm of the absorption pipette. The rate of passage is not materially changed by a 1-inch layer of liquid petrolatum floating on this surface of the reagent.

The magnitude of the error likely to occur under otherwise similar conditions is approximately proportional to the solubility of the inert gas in the reagent used, and when there is a choice of reagents this solubility should be considered. The magnitude of the error also depends upon many other variables, including the rate of absorption of the reactive gas, the composition of the reagent, the composition of the gas mixture, the form of apparatus employed, and the operating procedure. The data are not sufficiently complete to set up a general set of corrections for analyses performed under varying conditions but have been used to explain, within reasonable limits, the previously observed behavior of chromous solutions when these were used to absorb oxygen as reported in RP1112.

Fortunately, such commonly used reagents as potassium hydroxide and alkaline potassium pyrogallate will absorb but little nitrogen if the concentration of the alkali is sufficiently great. The concentration of potasssium hydroxide in both of these reagents should, therefore, be kept as high as laboratory conditions permit.

Washington, April 4, 1938. 